ENSV TEADUSTE AKADEEMIA TOIMETISED. XVI KOIDE KEEMIA * GEOLOOGIA. 1967, NR. 2

НЗВЕСТИЯ АКАДЕМИИ НАУК ЭСТОНСКОИ ССР. ТОМ ХVI ХИМИЯ * ГЕОЛОГИЯ. 1967, № 2

\author{
B. КЫРВEЛ, H. КЫРВЕЛ
}

\title{
ЛИТОСТРАТИГРАФИЯ НИЖНЕЛЛАНДОВЕРИЙСКИХ ОТЛОЖЕНИИ В ВОСТОЧНОЙ ЭСТОНИИ
}

В центральной части Пандивереской возвышенности, а также на ее южном и восточном склонах выходят отложения нижней части лландювери - юуруский $\left(\mathrm{G}_{\mathrm{I}}\right)$ и тамсалуский $\left(\mathrm{G}_{\mathrm{II}}\right)$ горизонты. Стратиграфия этих отложений изучена многими исследователями и мы имеем ряд стратиграфических схем их расчленения.

Так, в 1949 г. Р. Мянниль, отчасти следуя более ранним исследованиям Э. Розенштейн (Rosenstein, 1940), подразделил юуруский горизонт на три части, выделив (снизу вверх) койгиский, варболаский и пургаский «подгоризонты» (см. также Аалоэ, 1958). А. Аалоэ (1958), однако, ограничивает объем юуруского горизонта только варболаскими слоями, относя койгиские слон к поркунискому горизонту, а пургаские - к тамсалускому.

В юуруском горизонте на территории Эстонии А. Аалоэ выделяет две региональные пачки - варболаские слои, распространяющиеся на Пандивереской возвышенности и в районах к западу от нее, и паасвереские слои, распространяющиеся к востоку от этой возвышенности. Основанием для выделения паасвереских слоев служили старая каменоломня в окрестностях дер. Паасвере (ныне эта каменоломня полностью заросла), а также разрезы буровых скважин Вяйке-Маарья № 4 и Козе.

Породы, вскрытые скважиной Вяйке-Маарья № 4 и отвечающие паасвереским и козеским слоям схемы А. Аалоэ, литологически и фаунистически весьма сходны с варболаскими слоями и должны быть отнесены к последним (ср. также Аалоэ, 1958, стр. 86, 87 и 92). Что же касается отложений разреза скважины Козе, то они хорошо сопоставляются с соответствующими отложениями в скважинах, расположенных южнее и юго-восточнее Пандивереской возвышенности (скважины Яаска, Паламузе, Пауаствере и др.) (см. рис. 1). Как указывается ниже, характерной чертой всех этих разрезов (в том числе и разреза скв. Козе) является их литологическое однообразие в пределах всего разреза юуруского и тамсалуского горизонтов, сложенного глинистыми известняками и мергелями и прослойками глин. Поэтому здесь отсутствуют литологические критерии для подразделения юуруского и тамсалуского горизонтов и на всей обширной территории южной, юговосточной и юго-западной части Эстонии юуруский и тамсалуский горизонты в настоящее время литологически и палеонтологически не расчленяются (см. Каяк, 1962; Кала и др., 1962; Аалоэ и Кальо, 1962). 


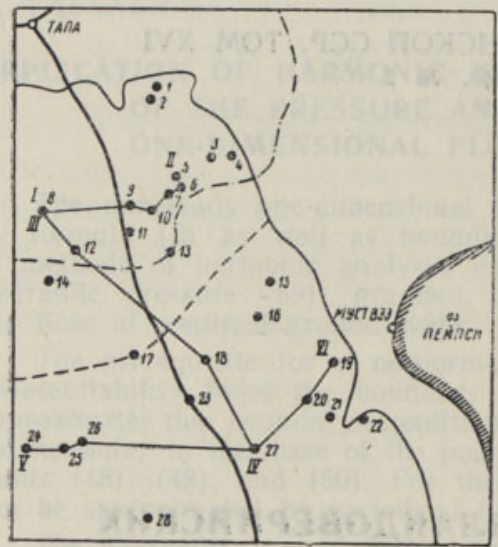

Ia $I, \frown 2, \ldots, \ldots$

Рис. 1. Схема расположения буровых скважин: 1 - Пандивере: 2 - Коону; 3 - Роху: 4 - Келлавере; 5 - Авандузе; 6 - Симуна; 7 - Хирла; 8-Эллавере; 9 - Камарику: $10-$ Вяйке-Таммнку: 11 - Ракке: 12 - Пийбе; 13 - Эмумяэ; 14 - Острику; 15 - Метсакюла; 16 - Садала; 17 - Кярде: 18 - Лоппе: 19 - Яаска; 20 - Туулавере; 21 - ОЙя; 22 - Козе: 23 - Иыгева: 24 - Пауаствере: 25 - Сулуствере: 26 - Қаавере; 27 - Паламузе; 28 - Курси. 1 - линии разрезов; 2 - северная граница распространения нижнелландоверийских отложений; 3 - северная граница распространення пауастверескоЯ̆ пачки; 4 контур восточной части Пандивереской возвышенности.

На этом основании авторы настоящей статьи считают, что отложения, названные А. Аалоэ паасверескими и козескими слоями, образуют единую литостратиграфическую единицу, для которой целесообразно сохранить название «козеская пачка». Название «Паасвере» для данной единой толщи неприемлемо, так как в каменоломнях в деревне Паасвере обнажаются лишь отложения поркуниского горизонта, а наличие пород юуруского горизонта в ближайших ее окрестностях последующими работами не подтверждено.

Нижняя граница юуруского горизонта, тем самым и нижняя граница силура в Восточной Әстонии, проводится авторами по подошве скрытокристаллических (афанитовых) известңяков (верхняя часть койгиского «подгоризонта» Р. Мянниля), за которыми в настоящей статье сохранено название «Койги». По мнению авторов, в пользу этой точки зрения говорит, во-первых, то, что скрытокристаллические известняки связаны постепенными переходами с вышележащими глинистыми извєстняками юуруского горизонта; во-вторых, скрытокристаллические известняки в Восточной Әстонии перекрывают разнофациальные отложения, нижележащего поркуниского горизонта. За силурийский возраст скрытокристаллических известняков совместно с нижележащими песчаниками высказывался ряд исследователей (Jaanusson, 1956; Martna, 1957). Отнесение их к поркунискому горизонту (Аалоэ, 1958; Рыымусокс, 1960 и др.) ставится некоторыми исследователями под сомнение и в последнее время (Мянниль, 1962).

Ниже дается краткая литостратиграфическая характеристика отложений юуруского и тамсалуского горизонтов в районе Пандивереской возвышенности.

Койгиская пачка $\left(\mathrm{G}_{\mathrm{I}} \mathrm{K}\right)$ сложена скрытокрнсталлическими (афанитовыми) известняками с тонкими извилистыми прослоями мергеля. Характерен раковистый излом известняков; встречаются волосовидные прожилки кальцита. Порода очень тонкослопстая. Цвет породы в основном желтовато-серый. В скважинах Роху, Авандузе и Симуна известняки койгиской пачки подверглись сильной доломитизации и представлены окремнелыми доломитами. Встречаются мелкие обломки брахионод, ругоз и мшанок. На Пандивереской возвышенности породы койгиской пачки подстилаются песчаными отложениями, а в скважине Лопне - мелкозернистыми слабо глинистыми известняками поркуниского горизонта. Верхняя граница койгиской пачки на возвышенности проводится по подошве узловатых известняков варболаской пачки. В скважине Лоппе койгиская пачка перекрывается мелкозернистыми доломитами, залегающими в основании козеской пачки (см. рис. 2 и 3 ).

Мощность койгиской пачки в отдельных скважинах составляет (в метрах): Эллавере $-2,4$, Симуна - 2,1, Камарику $-1,8$, Вяйке-Таммику $-1,8$, Авандузе 1,7 , Хирла - 1,4, Лоппе - 1,3, Пыгева - 0,7, Острику $-0,6$. 


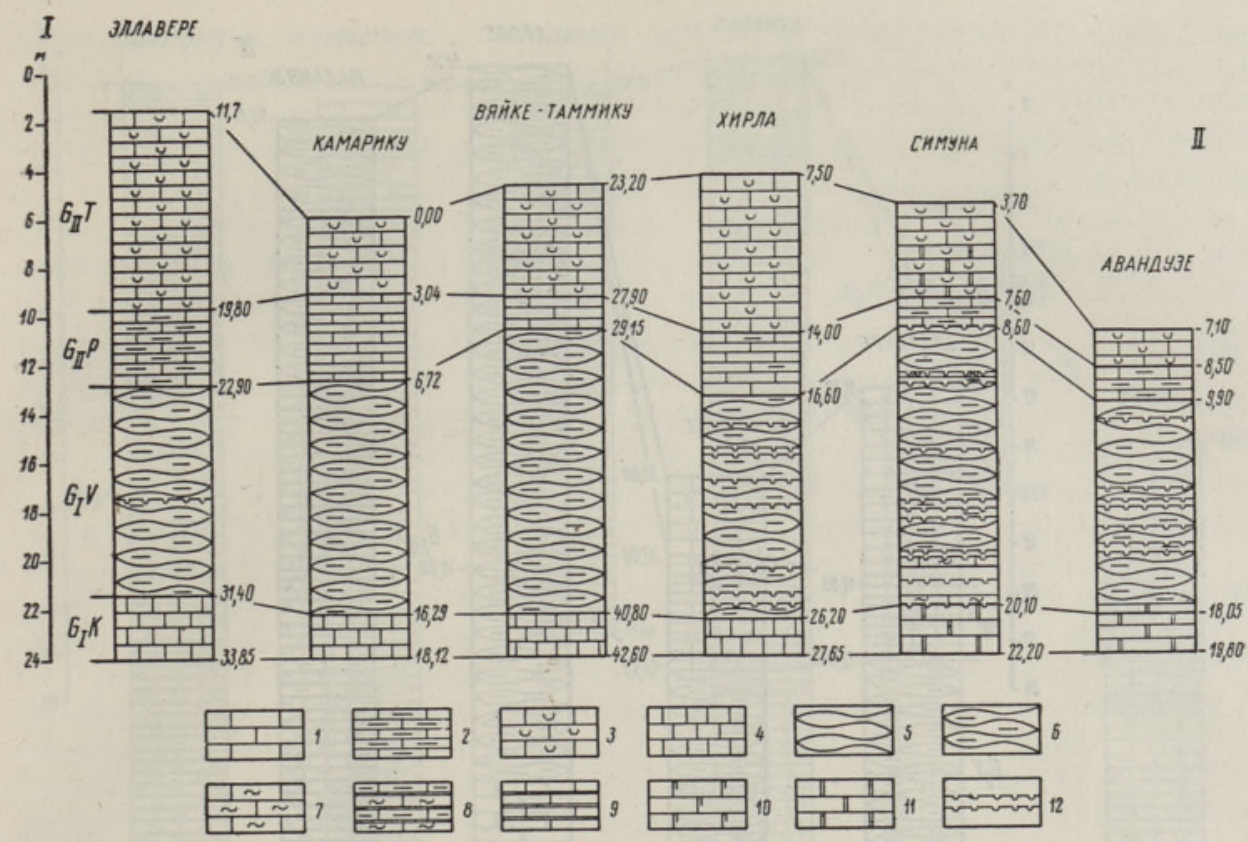

Рис. 2. Сопоставление разрезов нижнелландоверийских отложений по линии I-II: 1 - известняк мелкозернистый. тонкослоистый; 2 - то же, глинистый; 3 - известняк пентамерусовый; 4 - известняк скрытокристаллический; 5 - известняк тонкослонстый с узловатой текстурой: 6 - то же, глннистый: 7 - мергель; 8 - переслаивание глинистого извєстняка, мергеля и известковой глины; 9 - переслаивание мелкозернистого известняка с известковой глиной; 10 - нзвестняк доломитизированный; 11 - доломит; 12 - поверхности перерыва.

Варболаская пачка $\left(\mathrm{G}_{\mathrm{I}} \mathrm{V}\right)$. В пределах рассматриваемого нами района варболаская пачка распространяется только на Пандивереской возвышенности западнее нее. Южнее и юго-восточнее она постепенно заменяется козеской пачкой.

Варболаская пачка сложена глинистыми тонкослоистыми комковатыми (характерный признак!) известняками зеленовато-серого цвета, иногда доломитизированными, содержащими прослои мергелей. В большинстве случаев для этих отложений характерно большое количество окаменелостей - брахиопод, гастропод, мшанок и кораллов.

В скважине Роху варболаская пачка сложена глинистыми пестро окрашеннымі (в коричнево-фиолетовый, зеленовато- и желтовато-серый цвета) доломитами, обладающими тонко-, мелко- и среднезернистой структурой. Доломиты содержат тонкие извилистые прослои мергеля. В нижней части доломит содержит включения белого халцедона размерами от $0,5 \times 1$ до 3 и $4 \mathrm{~cm}$ различной (чаще округлой) формы. Характерны коричнево-красные разводы и пятна гидроокислов железа.

Характерны для варболаской пачки многочисленные пиритизированные поверхности перерыва.

Нижняя граница варболаской пачки проводится по кровле скрытокристаллических известняков койгиской пачки. Иногда к этому уровню приурочепы поверхности переры்ва (скв. Симуна).

Мощность варболаской пачки составляет (в метрах): в скважине Симуна $-11,5$, Вяйке-Таммику $-10,65$, Пийбе $-10,3$, Пандивере $-10,2$, Хирла $-9,6$, Қамарику 9.57, Эллавере - 8,5, Авандузе - 8,15.

Пургаская пачка $\left(\mathrm{G}_{\mathrm{II}} \mathrm{P}\right)$, как и варболаская, распространяется на Пандивереской возвышенности и западнее нее. Пачка сложена мелкозернистыми тонкослоистыми детритовыми в основном глинистыми известняками, обладающими тонкой слоистостью за счет тонких прослоев мергеля. Характерным признаком известняков пургаской пачки является их пестрая окраска (серо-бурые и фиолетово-серые цвета). 


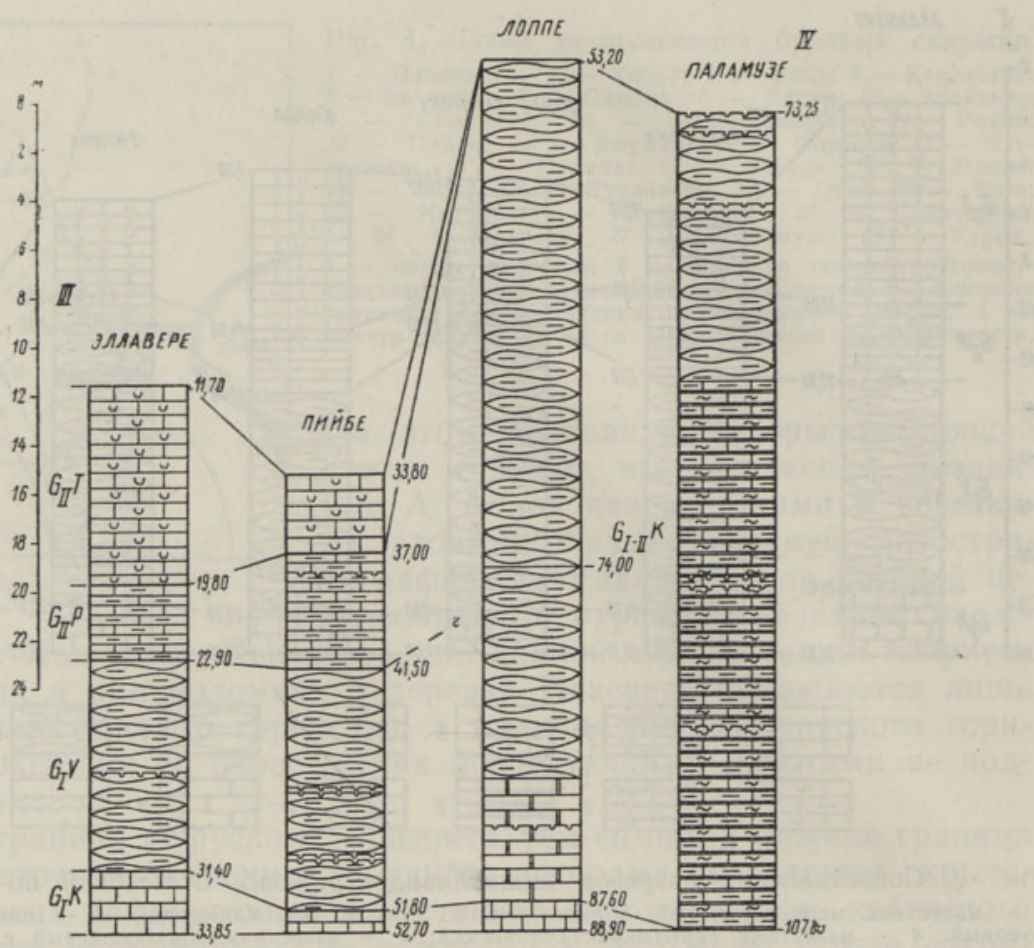

Рис. 3. Сопоставление разрезов по линии III--IV (условные обозначения см. рис. 2).

В скважинах Роху, Келлавере и Коону пургаская пачка представлена мелкокристаллическими доломитами. Окраска их пестрая (светло-серые, зеленовато-серые, коричнево-красные и фиолетовые тона). Доломиты содержат примесь глины, а также многочисленные тонкие извилистые мергельные прослойки зеленовато-серого и буросерого цвета.

Мощность пачки в скважине Пийбе - 4,5 м, Камарику - 3,7, Эллавере - 3,1, Ракке $-1,8$, Хирла $-2,6$, Авандузе $-1,4$ и Симуна $-1,0$ м.

Таммикуская пачка $\left(\mathrm{G}_{\mathrm{II}} \mathrm{T}\right)$ (так наз. бореалисовая банка) достигает наибольшего развития в центральной части Пандивереской возвышенности. Здесь она сложена г.авным образом биоморфными пентамерусовыми известняками, состоящими на 50 $80 \%$ из створок брахиопод Pentamerus borealis и их фрагментов. Мощность таммикуской пачки на Пандивереской возвышенности колеблется от 8,1 (скв. Эллавере) до 13,5 м (скв. Коону).

В карьере Тамсалу весь комплекс $(6,0 \mu)$ состоит из мелкокристаллического толстослоистого светло-серого, почти белого известняка, обильно насыщенного створками P. borealis, что придает породе конгломератный вид.

В некоторых скважинах (Симуна) породы таммикуской пачки сложены из доломитизированных разновидностей. В скважине Садала пачка представлена пестро окрашенными средне- и крупнозернистыми, сильно кавернозными доломитами мощностью 13,6 м. Из аналогичных доломитов сложена пачка и в скважинах Роху и Келлавере.

В отложениях таммикуской пачки скважин южного склона Пандивереской возвышенности отмечено увеличение терригенного компонента. Здесь вскрыты в некоторой степени глинистые известняки, содержащие редкие тонкие $(1-3$ см) прослои сцетлой известковой глины. Здесь же отмечено уменьшение мощности пачки: скв. Пийбе $-3,2$ м, Ракке $-5,3$, Вяйке-Таммику $-4,7$, Кярде $-4,4 м$. 


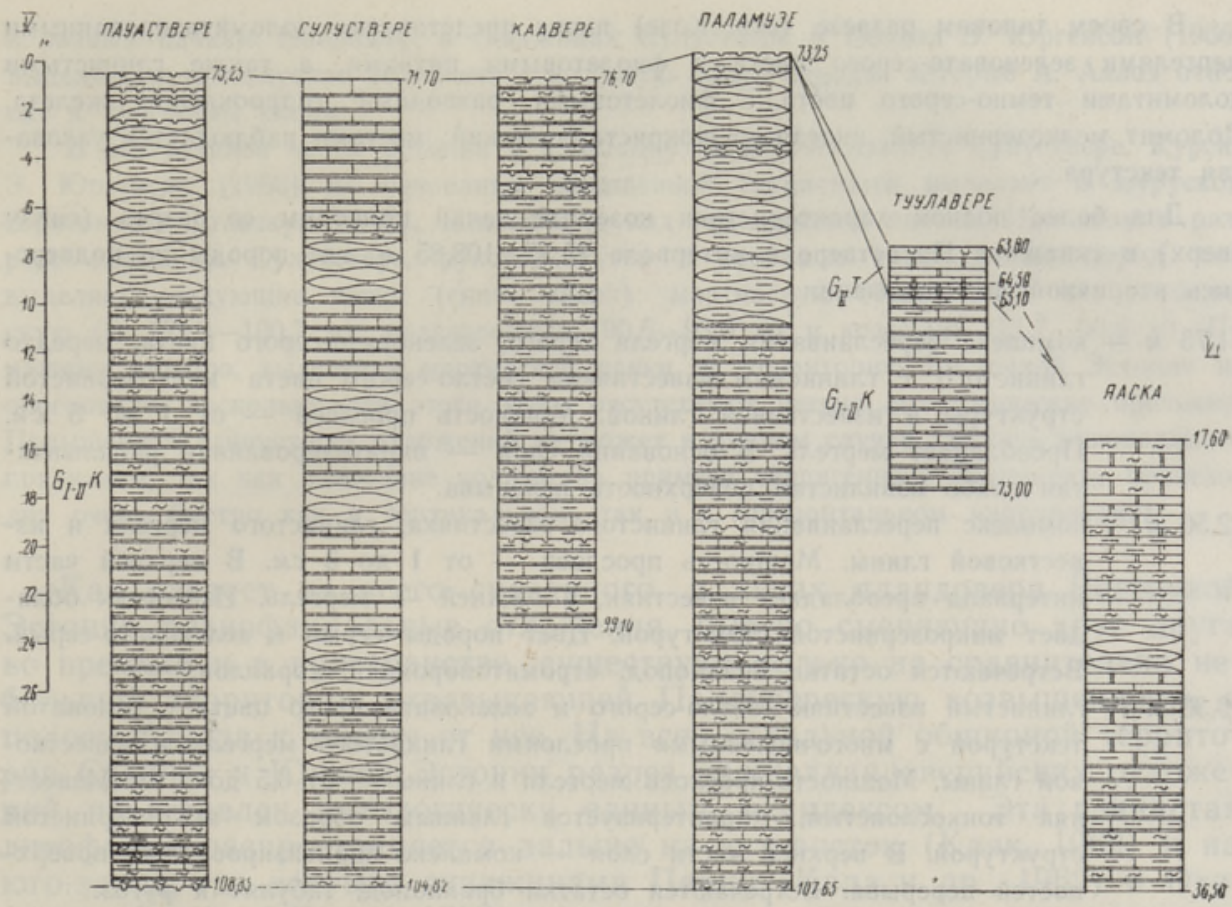

Рис. 4. Сопоставление разрезов по линии V-VI (условные обозначения см. рис. 2).

Юго-восточнее Пандивереской возвышенности таммикуская пачка представлена детритовыми известняками, местами глинистыми с прослоями глин. Известняки содержат небольшое количество $(\sim 20 \%)$ створок пентамерид, нередко перекристаллизованных (Ойя). В скважине Туулавере вскрыты мелко- и среднезернистые доломиты темно-серого и бежево-серого цвета с редкими створками пентамерид. Нижняя часть (0,6 м) сложена из мелкозернистого доломита.

Как видно из сказанного, на рассматриваемой территории таммикуская пачка имеет более широкое развитие, чем варболаская и пургаская пачки, распространяясь дальше на юго-восток. Отсутствует она лишь в самой южной части рассматриваемой территории (в скважинах Пауаствере, Сулуствере, Каавере, Курси, Паламузе, Лоппе и Козе).

Козеская пачка $\left(\mathrm{G}_{\mathrm{I}-\mathrm{II}} \mathrm{K}\right)$ слагает юуруский и тамсалуский горизонты в районе $\mathrm{K}$ юго-востоку и югу от Пандивереской возвышенности и вскрыта многочисленными буровыми скважинами (Козе, Пауаствере, Сулуствере, Курси, Паламузе, Лоппе и др.). Пачка представлена глинистыми известняками, переслаивающимися с мергелями и глинами. Мощность прослоев - от 1 до $3 \mathrm{~cm}$. Известняки обычно глинистые, местами дсломитизированные, светло-серой и зеленовато-серой окраски. Структура известняков микро-, реже мелкозернистая, мелкодетритовая. Текстура слоистая, местами желваковатая. В нижней части пачки иногда встречаются тонкие прослои глинистых известняков скрытокристаллической структуры с раковистым изломом.

Переслаивающиеся с известняками мергели обычно глинистые, тонкослоистые, зеленовато-серой окраски. Глины, ритмично чередующиеся с известняками и мергелями, по составу известковые, цвет их серый и зеленовато-серый; характерна тонкая слоистость и пластичность.

Для пачки характерны наличие многочисленных пиритизированных поверхностей перерыва, а также остатки кораллов, строматопороидей и брахиопод. 
В своем типовом разрезе (скв. Козе) пачка представлена доломитизированными мергелями зеленовато-серого цвета с фиолетовыми пятнами, а также глинистыми доломитами темно-серого цвета с фиолетовыми разводами гидроокислов железа. Доломит мелкозернистый, иногда мелкокристаллический; местами наблюдается узловатая текстура.

Для более полной характеристики козеской пачки приводим ее разрез (снизу вверх) в скважине Пауаствере в интервале 75,25-108,85 м, где породы не подверглись вторичной доломитизации.

1,75 $м$ - комплекс переслаивания мергеля серого, зеленовато-серого цвета, нередхо глинистого, с глинистым известняком светло-серого цвета мелкозернистой структуры и известковой глиной. Мощность прослоев - от 1 до 5 си. Преобладает мергель. В основании слоя - пиритизированная расплывчатая слабо извилистая поверхность перерыва.

22,50 м - комплекс переслаивания глинистого известняка, глинистого мергеля и известковой глины. Мощность прослоев - от 1 до 3 см. В верхней части интервала преобладает известняк, в нижней - мергель. Известняк обладает микрозернистой структурой. Цвет породы серый и зеленовато-серый. Встречаются остатки брахиопод, строматопороидей, кораллов.

9,35 м - глинистый известняк светло-серого и зеленовато-серого цвета с узловатой текстурой с многочисленными прослоями глинистого мергеля и известковой глины. Мощность прослоев мергеля и глины - от 0,5 до 2 см. Известняк тонкослоистый, характеризуется главным образом микрозернистой структурой. В верхней части слоя - комплекс пиритизированных поверхностей перерыва. Встречаются остатки брахиопод, табулят и ругоз.

В скважине Лоппе нижняя часть $(4,9$ м) козеской пачки представлена мелкозернистыми толстослоистыми светло-серыми доломитами.

Выше залегают глинистые мелкодетритовые мелкозернистые известняки узловатой текстуры с прослоями мергеля мощностью от 3 до $5 \mathrm{~cm}$.

Глинистые доломиты мелкозернистой структуры и узловатой текстуры встречечы в верхней части разреза скважины Яаска. Нижележащие глинистые мелкозернистые изеестняки часто доломитизированы; наблюдаются вишнево-красные пятна гидроокислов железа.

Нижняя граница козеской пачки имеет обычно переходный характер, но местами она маркируется поверхностями перерыва (Пауаствере). В разрезе скважины Лоппе нижняя граница пачки -проводится по кровле скрытокристаллических известняков. койгиской пачки.

Верхняя граница козеской пачки на большей части территории совпадает с верхней границей тамсалуского горизонта и литологически связана переходами с вышележащими глинистыми известняками нижней части райккюлаского горизонта. В сквджинах Пауаствере, Каавере и Паламузе верхняя граница пачки маркируется поверхностями перерыва. В зоне распространения таммикуской пачки (Туулавере, Садала) верхняя граница козеской пачки проводится по подошве глинистых известняков с пентамеридами.

Мощность козеской пачки составляет (в метрах): Паламузе - 34,4, Курси $36,6(107,1-70,5)$, Лоппе - 34,4, Пауаствере - 33,1, Каавере - 22,4 (неполная мощность).

Таким образом, козеская пачка на большей части территории своего распространения охватывает весь разрез юуруского и тамсалуского горизонтов. Подразделение этой литологически однородной толщи на паасвереские и козеские слои, предложенное А. Аалоэ, не подтверждается нашими наблюдениями.

Отсутствие четких литологических признаков, которые позволяли бы подразделять данную толщу, приводит к тому, что разные авторы относят одни и те же слои 
ж разным пачкам. Например, в скважинах Сулуствере и Иыгева Э. Юргенсон (1966) выделяет в тамсалуском горизонте в козескую пачку породы, которые А. Аалоэ относит к пургаским слоям.

В центральной части Эстонии и к востоку от нее (скважины Сулуствере, Курси) Э. Юргенсон (1966) на основании повышенной глинистости выделяет в юуруском горизонте мартнаскую пачку, залегающую под паасвереской пачкой. При этом в разрезе скважины Сулуствере, руководствуясь в основном глинистостью пород, она вьделяет следующие пачки (снизу вверх): мартнаскую $(100,7-105,2$ м); варболаскую (!) (93,9-100,7 $м$ ); паасверескую $(90,6-93,9$ м) и козескую $(71,7-90,6 м$ ). По нашему мнению, выделение мартнаской пачки на территорию Восточной Эстонии не обосновано, поскольку для этого здесь отсутствуют четкие литологические признаки. Псвышенная глинистость отложений не может в данном случае служить руководящим гризнаком, так как изменение количества примеси терригенного компонента происходит очень быстро как в вертикальном, так и в горизонтальном направлениях.

Как следует из всего сказанного, в низах лландовери Восточной Эстонии разнофациальные отложения, быстро сменяющие друг друга во времени и в пространстве, существуют только на сравнительно небольшой территории, охватывающей Пандиверескую возвышенность и полосу выхода к западу от нее. На всей остальной обширной территории Средней и Южной Эстонии разрез нижнелландоверийских отложений представлен литологически единым комплексом. Эта глинистая литофация распространяется дальше на юго-восток (Каяк, 1962) и на юrо-запад, где вскрыта скважинами Пярну (Кала и др., 1962) и Охесааре (Аалоэ и Кальо, 1962).

Фаунистический анализ этого единого комплекса проведен до сих пор недостаточно полно. Фаунистическое исследование разреза скважины Пярну показало, что комплекс фауны остракод, ругоз, строматопороидей, фавозитид и трилобитов является единым в пределах всей толщи юуруского и тамсалуского горизонтов, за исключением таммикуской пачки (Кала и др., 1962). Очень тесная связь между фауной юуруского и тамсалуского горизонтов существует и в полосе выхода этих горизонтов, на что указывали в разные времена разные авторы (Twenhofel, 1916; Teichert, 1928; Клааманн, 1959 и др.). Ввиду этого тамсалуский горизонт рассматривался некоторыми исследователями как фациальная разновидность юуруского горизонта, не имеющая самостоятельного стратиграфического значения.

На основании вышеизложенного авторы настоящей статьи не видят особых препятствий для рассматривания юуруских и тамсалуских отложений в качестве единого, юуруского горизонта.

\section{Л И Т Е Р А Т У Р А}

А ало э А. О., 1958. Стратиграфия юуруского $\left(\mathrm{G}_{\mathrm{I}}\right)$ и тамсалуского $\left(\mathrm{G}_{\mathrm{II}}\right)$ горизонтов силура Эстонской ССР, Тр. Ин-та геол. АН ЭССР, III.

А алоэ А. О. и Кальо Д. Л., 1962. Краткий обзор разреза силурийских отложений в скважине Охесааре (о-в Сааремаа), Тр. Ин-та геол. АН ЭССР, Х.

Кал а Э. А., Мен с К. А. и У ндр и т с Л. А., 1962. Стратиграфическая характеристика разреза скважины Пярну, Тр. Ин-та геол. АН ЭССР, Х.

К ла а м ан н Э. Р. 1959. О фауне табуллт юуруского и тамсалуского горизонтов, Изв. АН ЭССР. Серия техн. и физ.-матем. наук, VIII, № 4.

Каяк К. Ф., 1962. К геологии Юго-Восточной Эстонии (по данным глубокого бурения), Тр. Ин-та геол. АН ЭССР, Х.

М лнни ль Р. М., 1962. Фаунистическая характеристика поркуниского горизонта, Тр. Ин-та геол. АН ЭССР, Х.

Р ы ы у с о к с А. К., 1960. Стратиграфия и палеогеография ордовика Эстонской ССР, Докл. сов. геологов на XXI сессии Междунар. геол. конгресса, Проблема 7 , Л. 
Юргенсон. Э. А., 1965. Литология лландоверийских отложений Эстонии, Таллин. $\mathrm{J}$ a a n u s s o n V., 1956. Untersuchungen über den oberordovizischen Lyckholm-Stufenkomplex in Estland, Bull. Geol. Inst. Uppsala, Vol. XXXVI.

Martna J., 1957. Notes on the Upper Ordovician, and Lower Silurian of the Tapa district, Estonia, Geol. Fören. Stock. Förh., Bd. 79.

Rosenstein E., 1940. Andmed Juuru lademe kohta, Eesti Loodus, nr. 4/5.

Teichert G., 1928. Stratigraphische und paläontologische Untersuchungen im unteren Gotlandium (Tamsal-Stufe) des westlichen Estlands und der Insel Dagö, Neues Jahrb. Mineral., Geol. und Paläontol., Beilageband 60, Abt. B.

Twenh of el W. H., 1916. Expedition to the Baltic Provinces of Russia and Scandinavia, 1914, Bull. Mus. Compar. Zool. Harward College, vol. VI, No. 4.

Управление геологии

Совета Министров Эстонской ССР
Поступила в редакцию 30/IX 1966

V. KORVEL, N. KORVEL

\section{ALAMLÃNDOUVERI SETETE LITOSTRATIGRAAFIA IDA-EESTIS}

Alamländouveri setted on Pandivere kõrgustikul esindatud juuru ja tamsalu lademetega. Viimaste stratigraafiat on käsitlenud paljud autorid (E. Rosenstein, A. Aaloe, R. Männil jt.), mille tulemusena eksisteerib mitmeid, mõnevoorrra üksteisest erinevaid detailsema jaotuse skeeme. Tuginedes läbitöötatud puurprofiilide materjalidele (joon. 1-4), oleks autorite arvates öigem Ida-Eestis juuru ladet alustada koigi kihistikuga, mille paljud uurijad seni on arvanud porkuni lademesse. Kihistik koosneb põhiliselt peitkristallilistest lubjakividest, kohati dolomiidistunud lubjakividest ja dolomiitidest. Kihistu paksus kõigub $0,6-2,4 \mathrm{~m}$ piires.

Koigi kihistikul lasub Pandivere kōrgustikul ja sellest läänes varbola kihistik, mis koosneb muguljatest savikatest lubjakividest merglivahekihtidega ja sisaldab rohkesti mitmesuguseid kivistisi. Kihistiku paksus antud piirkonnas on $8,15-11,5 \mathrm{~m}$.

Varbola kihistikul lasub samas piirkonnas tamsalu lademe purga kihistik kirjuvärviliste ōhukesekihiliste lubjakividega. Kihistiku paksus on $1,0-3,7 \mathrm{~m}$. Ulatuslikumalt on vaadeldud alal levinud tammiku kihistik, nn. pentaamerus-kehvel, biomorfsete lubjakividega. Kihistiku paksus kōigub $3,2-13,5 \mathrm{~m}$ piires.

Pandivere kõrgustikust kagu ja lōuna poole levib kose kihistik, mis ühendab juuru ja tamsalu lademeid, olles vastav endistele paasvere (juuru lademes) ja kose (tamsalu lademes) kihistikule. Kose kihistikule on iseloomulik savikate lubjakivide ja merglite rütmiline vaheldus ning arvukate püriidistunud katkestuspindade esinemine. Kohati esineb dolomiidistumist. Kihistiku paksus on $33,1-36,6 \mathrm{~m}$.

Arvestades nii omi kui ka teiste (K. Kajak, E. Kala, A. Aaloe, D. Kaljo) uurimistulemusi, on põhjust vaadelda juuru ja tamsalu lademeid ühtse juuru lademena, milles tamsalu lade kujutaks edast ainult fatsiaalset erimit.

\section{KORVEL, N. KORVEL}

\section{LITHOSTRATIGRAPHY OF LOWER LLANDOVERIAN STRATA IN EAST ESTONIA}

On the elevation of Pandivere the Lower Llandovery is represented by Juuru and Tamsalu Stages. The stratigraphy of the strata of the Juuru Stage has been dealt with by a number of authors (E. Rosenstein, A. Aaloe, R. Männil and others), and. as a result there exist several detailed, though somewhat varying schemes of their classification. On the basis of the studied boring sequences (figs $1-4$ ), the present authors consider it to be more appropriate to start the Juuru Stage in East Estonia with the Koigi Member, which has up to now been correlated with the uppermost part of the Porkuni Stage by several authors. The member consists mainly of cryptocrystalline limestones, and in places of dolomitized limestones and dolomites. The thickness of the member fluctuates within the limits of $0.6-2.4$ metres.

On the Pandivere elevation and to the west of it the Koigi Member is followed by the Varbola Member, which consists of nodular clayey limestones with marl 
intercalations and contains abundantly various fossils. The thickness of the member in the given region is $8.15-11.5 \mathrm{~m}$.

In the same region, the Varbola Member is overlain by the Purga Member (of the Tamsalu Stage) consisting of many-coloured, thin-laminated limestones. Its thickness is $1.0-3.7 \mathrm{~m}$. The Tammiku Member, widely distributed over the areas studied, consists of Pentamerus limestones of biomorphous texture. The thickness of the Tammiku Member is $3.2-13.5 \mathrm{~m}$.

In the southeast and south of the Pandivere elevation the whole sequence of the Juuru and Tamsalu Stages is represented by the Kose Member which is characterized by a cyclic alternation of nodular limestones and marls as well as by an occurrence of numerous pyritized discontinuity surfaces. In places dolomitization occurs. The thickness of the member is $33.1-36.6 \mathrm{~m}$.

Taking into account the results of the researches of the present authors as well as those by other investigators (K. Kajak, E. Kala, A. Aaloe, D. Kaljo), there is enough evidence to consider the Juuru and Tamsalu strata as a single Juuru Stage, in which the Tamsalu "Stage" forms but a facial variation. 